\title{
Genotyping guided ripretinib directly after the progression of first-line imatinib therapy in advanced gastrointestinal stromal tumor: a case report
}

\author{
Shaoqing Huang ${ }^{1 \#}$, Xiaodan Guo ${ }^{1 \#}$, Yanzhe $\mathrm{Xia}^{2}$, Li Ding ${ }^{3}$, Ertao Zhai ${ }^{1}$, Sile Chen ${ }^{1}$, Yulong $\mathrm{He}^{1}$, \\ Shirong Cai ${ }^{1}$, Xinhua Zhang ${ }^{1}$ \\ ${ }^{1}$ Department of Gastrointestinal Surgery, The First Affiliated Hospital of Sun Yat-sen University, Guangzhou, China; ${ }^{2}$ Department of Pharmacy, \\ The First Affiliated Hospital of Sun Yat-sen University, Guangzhou, China; ${ }^{3}$ Department of Pathology, The First Affiliated Hospital of Sun Yat-sen \\ University, Guangzhou, China \\ "These authors contributed equally to this work. \\ Correspondence to: Xinhua Zhang. Department of Gastrointestinal Surgery, The First Affiliated Hospital of Sun Yat-sen University, Guangzhou, \\ China. Email: zhangxinhua@mail.sysu.edu.cn.
}

\begin{abstract}
Gastrointestinal stromal tumor (GIST) is the most common mesenchymal tumor of the gastrointestinal tract. Surgery and tyrosine kinase inhibitor (TKI) therapy are the main choices of treatment. However, the long-term use of TKIs is prone to drug resistance. Herein, we report the case of a 47-yearold female with primary gastric GIST with liver metastases since June 2015. The patient achieved disease control under imatinib therapy and underwent primary lesion resection. She took postoperative imatinib maintenance therapy, but discontinued imatinib for 10 months about 2 years after surgery. The patient suffered from disease progression in May 2019, with recurrence of liver metastases and new abdominal metastases. From then on, imatinib was resumed and partial response (PR) persisted for another 2 years. The patient subsequently experienced tumor progression due to secondary KIT exon 17 mutation confirmed by tissue biopsy and circulating tumor DNA (ctDNA) detection. After multidisciplinary team discussion, the patient received ripretinib as a second-line therapy, and ctDNA monitoring demonstrated that the KIT mutations turned negative. After disease control from ripretinib for $2+$ months, she underwent cytoreductive surgery (R0/1) and received ripretinib maintenance treatment postoperatively. We believe that this case provides a reference value for individualized ripretinib precise therapy according to mutational analysis after the progression of first-line GIST treatment, and ctDNA can predict effectiveness to guide treatment.
\end{abstract}

Keywords: Gastrointestinal stromal tumor (GIST); imatinib; ripretinib; circulating tumor DNA (ctDNA); case report

Submitted Dec 03, 2021. Accepted for publication Jan 18, 2022.

doi: 10.21037/atm-21-6960

View this article at: https://dx.doi.org/10.21037/atm-21-6960

\section{Introduction}

Gastrointestinal stromal tumors (GISTs) are the most common mesenchymal tumors of the alimentary tract, and are more common in the stomach (50-60\%) (1). The liver and peritoneum are the most common metastatic sites after radical resection, and $70-80 \%$ of activating mutations in KIT and PDGFRA (platelet derived growth factor receptor alpha) are considered the main oncogenic drivers of GIST (2). Imatinib (IM) is the first-line standard treatment for GIST. Although imatinib is effective in many patients with GISTs, tumor resistance to imatinib is common (3).

Ripretinib (RIP) is a type II switch-controlled tyrosine kinase inhibitor (TKI) that aims to control broad-spectrum mutations in KIT and PDGFRA (4). Preclinical studies show that ripretinib can effectively inhibit all currently known KIT/PDGFRA subtype mutations and limit the proliferation of cell lines driven by gene mutations (5). In the phase I trial (NCT02571036), ripretinib showed 

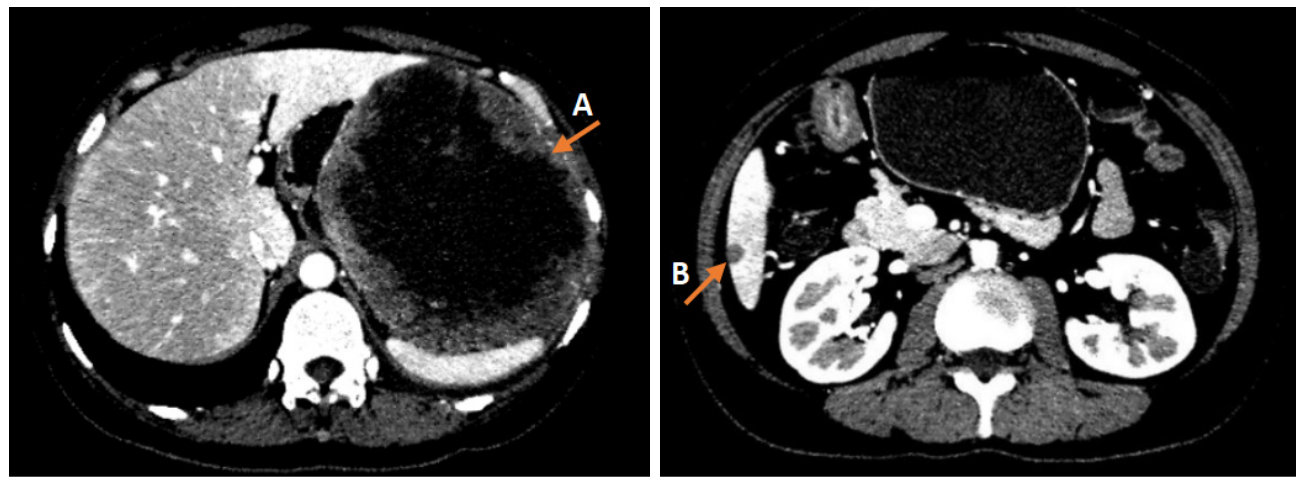

Figure 1 The radiological findings of the current case. A: a tumor about $12.4 \mathrm{~cm} \times 12.9 \mathrm{~cm}$ in size between the greater curvature of the gastric fundus and the spleen; B: metastases in liver S5/6.

preliminary clinical benefits in patients with heterogeneous drug-resistant KIT mutations. In phase III INVICTUS (NCT03353753) and phase IV bridging trial in China, ripretinib was proved with combined efficacy and safety $(6,7)$. It has a favorable response in patients with refractory advanced GIST, and has become an innovative treatment for heterogeneity of the drug resistance mechanism.

To date, the sensitivity and specificity of response of TKI in GIST evaluated by imaging are limited. It is relatively difficult to obtain biopsy specimens, and there is no confirmed biomarker to guide GIST treatment and prognosis (8). CtDNA is a biomarker with high specificity and sensitivity. CtDNA detection can theoretically overcome the limitations of tissue biopsy, provide the same or even more molecular and genetic information, and allow dynamic evaluation of the characteristics of tumor molecules over time (9). However, ctDNA test is not widely used in GIST because there is less exfoliated ctDNA than other tumors and low detection rate in peripheral blood (10).

Herein, we introduce a recent case of successful application of molecular detection prediction, individualized second-line treatment with ripretinib after first-line imatinib progression, dynamic monitoring of efficacy with ctDNA, and cytoreductive surgery, which may provide reference for the selective application of ripretinib combined with surgery in later-line treatment for metastatic GISTs.

We present the following article in accordance with the CARE reporting checklist (available at https://atm. amegroups.com/article/view/10.21037/atm-21-6960/rc).

\section{Case presentation}

In June 2015, a 47-year-old female who had "repeated abdominal pain and distension more than 1 year" was diagnosed with GIST with liver metastases. At the time of diagnosis, computerized tomography (CT) showed a tumor (approximately $12.4 \mathrm{~cm} \times 12.9 \mathrm{~cm}$ in size) between the greater curvature of the gastric fundus and the spleen with metastases in the liver S5/6, and core-needle biopsy confirmed GIST (Figure 1). Immunohistochemistry suggested tumor cells CD117, CD34, PDGFR, and Ki67 were all positive. Based on the GIST management guidelines, the patient began to take imatinib $400 \mathrm{mg} / \mathrm{d}$ as a first-line therapy. During 8 months of imatinib therapy, regular reviews showed that the tumor had significantly reduced. The assessment of imatinib therapy was partial response (PR), and the patient then underwent resection of the gastric fundus tumor and wedge gastrectomy in February 2016 in a tertiary teaching hospital, while the liver metastases were not resected (R2). She then received postoperative imatinib maintenance treatment and regular surveillance showed disease control within 2.5 years. However, from July 2018, the patient refused to continue imatinib treatment because of side effect like alopecia, nausea, and fatigue.

In May 2019, at which point imatinib treatment had been discontinued for 10 months, CT scanning indicated enlargement and new liver and multiple abdominal metastases. Thereafter, imatinib $300 \mathrm{mg} / \mathrm{d}$ was resumed regularly, with acceptable plasma imatinib concentration. The patient regained PR from the therapy. However, on May $18^{\text {th }}, 2021$, CT and PET-CT indicated new metastasis (about $4.3 \mathrm{~cm} \times 4.4 \mathrm{~cm}$ in size) in the hepatorenal recess, with multiple small lesions in the abdominal cavity. The former liver metastases were still stable. Biopsy of the lesion from the hepatorenal recess confirmed GIST, with Ki-67 

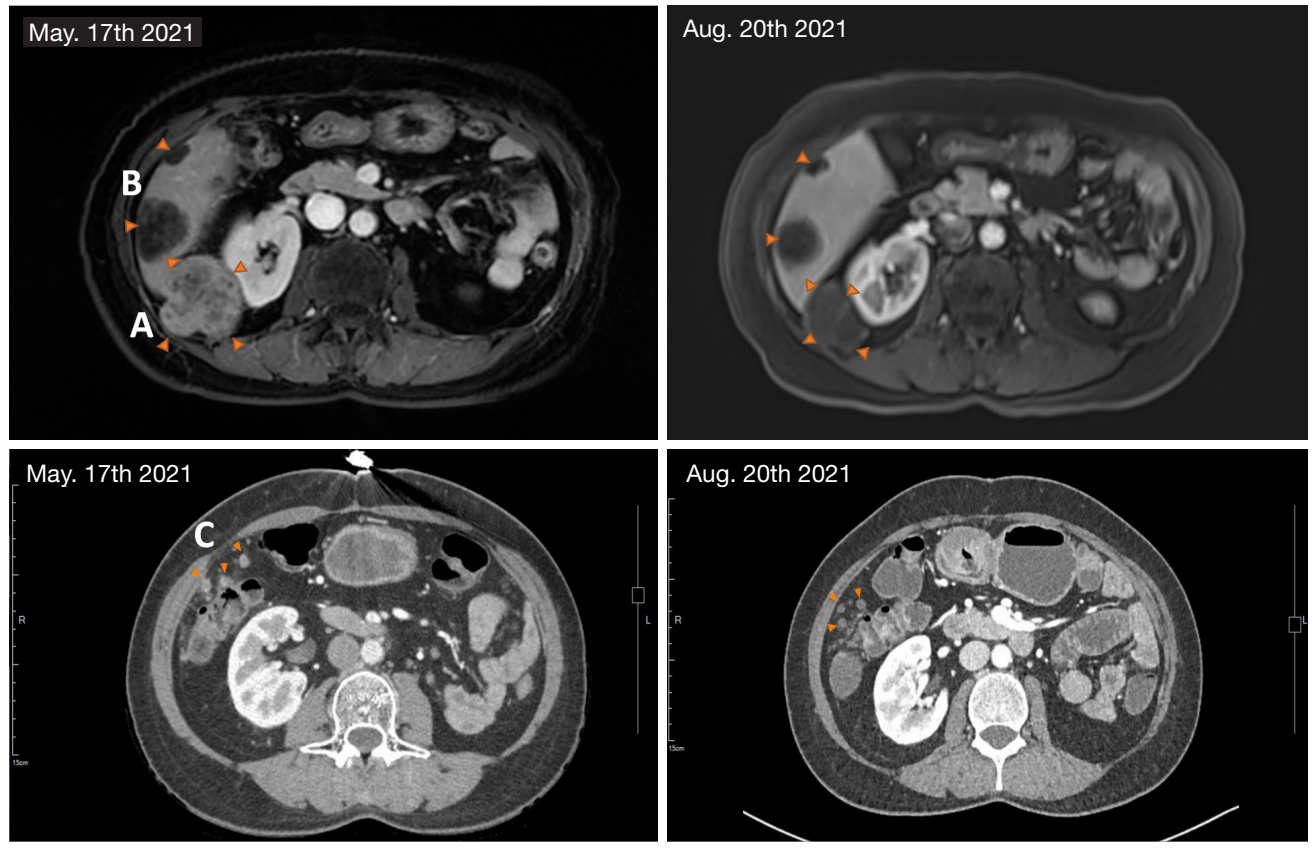

Figure 2 Imaging results after RIP treatment for $80^{+}$days on August $20^{\text {th }}, 2021$, compared with the baseline results of May $17^{\text {th }}$, 2021. A: metastasis in the hepatorenal recess had shrunk by 17\% in diameter; B: metastases in liver S1/S5/S6 were roughly the same size as before; C: multiple metastatic lesions in abdominal cavity were smaller than before. RIP, ripretinib.

$50 \%$ positive. Mutational analysis demonstrated that the mutation abundance of KIT exon 11 K558_E562del and 17 D816del were $4.0 \%$ and $2.6 \%$, respectively, in peripheral blood (ctDNA), $49.7 \%$ and $26.1 \%$, respectively, in tissue samples. Also, nonsense mutation in PDGFRB exon 3 tested positive in ctDNA.

A multi-disciplinary team (MDT) discussion was conducted for the case. This patient had extensive progression of gastric GIST with liver metastases after firstline treatment. The preferred treatment was deemed to be second-line systematic targeted therapy. However, there were just small amount of progressive lesions with relatively low tumor burden, including the original lesions and new lesions, which were potentially resectable. If there was an opportunity for effective systemic treatment, another satisfactory cytoreductive surgery (CRS) might increase the patient's benefit and prolong survival. The standard second-line therapy, sunitinib (SU), was not sensitive to KIT exon 17 mutation. Limited evidence has suggested that the third-line regorafenib (REG) and fourth-line RIP may both be sensitive to this mutation, but the objective response rate (ORR) of RIP may be better and its safety was certainly superior to that of REG. The MDT discussion recommended treatment with RIP or REG, with RIP being more favorably recommended.

After MDT discussion and sufficient explanation, the patient provided informed consent and began to take RIP $150 \mathrm{mg} / \mathrm{d}$ from June $1^{\text {st }}$, 2021. In order to obtain earlier assessment of RIP therapy, plasma ctDNA test after 2 weeks of treatment showed that the mutation abundance of both KIT exon 11 and 17 decreased to zero. Magnetic resonance imaging (MRI) indicated stable disease (SD) after 4 weeks of treatment. Repeated MRI and CT scans after 80 days of RIP treatment showed that the lesion in hepatorenal recess had shrunk about $17 \%$ in diameter which had met treatment expectation (Figure 2). After the second MDT discussion, the patient underwent laparotomy in our hospital.

The main imatinib-resistant lesion was located in the hepatorenal recess, which showed effective changes after treatment. The texture was soft, surrounded by a thickened peritoneal capsule and fascia. Most of the other scattered peritoneal implant metastases were located in the rightsided greater omentum, and a few were located in the right diaphragmatic peritoneum. Liver metastases in S1, S5, and S6 were observed to have had effective changes under targeted therapy. All visible lesions were removed and R0/1 resection was accomplished (Figure 3).

Postoperative pathology confirmed GIST. Plasma 
ctDNA before surgery indicated that the mutation abundance of both KIT exon 11 and 17 deletion remained at zero, while PDGFRB exon 3 had increased slightly from $0.9 \%$ to $1.0 \%$ (Figure 4 ). No new KIT mutations were found in the analysis of all resected tissues (Table 1).

The MDT meeting was held again after the second operation. Considering that there was secondary KIT exon 17 mutation in multiple peritoneal metastases, suggesting

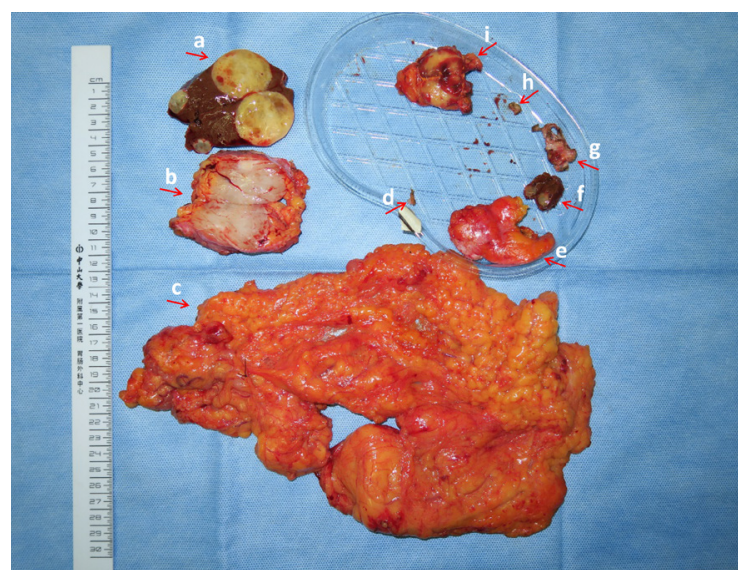

Figure 3 The lesions resected in the second operation. a: metastatic tumors of liver S5 and S6; b: hepatorenal recess metastasis; c: omentum and small metastatic lesions; d: diaphragmatic tubercle [1]; e: ligamentum teres hepatis; f: metastatic tumor of liver S1; g: diaphragmatic peritoneal tubercle; h: diaphragmatic tubercle [2]; i: adrenal tumor (myelolipoma). that drug-resistant lesions were widely distributed, it was recommended to resume RIP treatment. The patient recovered well and was discharged on the $8^{\text {th }}$ postoperative day.

During RIP treatment, mild adverse reactions, such as alopecia, palmar-plantar erythrodysesthesia syndrome, and mild anemia [hemoglobin (Hb): 106-113 g/L] were observed. The patient tolerated the therapy well and there were no dosing interruptions. The patient stopped RIP for 5 days before the operation, and resumed RIP therapy (maintained at $150 \mathrm{mg} / \mathrm{d}$ ) on the $7^{\text {th }}$ day postoperatively.

To sum up, we made a brief flowchart of the patient's diagnosis and treatment process (Figure 5).

All procedures performed in this study were in accordance with the ethical standards of the institutional and/or national research committee(s) and with the Helsinki Declaration (as revised in 2013). Written informed consent was obtained from the patient for publication of this case report and any accompanying images. A copy of the written consent is available for review by the editorial office of this journal

\section{Discussion}

The activation of genomic alterations in KIT or PDGFRA drives cellular growth in most GISTs. Targeted therapy with tyrosine kinase inhibitors (TKIs) has revolutionized the treatment of GIST; imatinib was approved for patients with KIT-positive unresectable and/ or metastatic malignant GIST (11). Although more than $80 \%$ of patients with

Table 1 Mutation types and their abundance in all resected tissues

\begin{tabular}{|c|c|c|c|c|c|c|c|c|c|}
\hline Gene & AAchange & $\begin{array}{c}\text { Diaphragmatic } \\
\text { tubercle [1] }\end{array}$ & $\begin{array}{c}\text { Diaphragmatic } \\
\text { peritoneal } \\
\text { tubercle }\end{array}$ & $\begin{array}{c}\text { Diaphragmatic } \\
\text { tubercle [2] }\end{array}$ & $\begin{array}{c}\text { Metastatic } \\
\text { tumor of } \\
\text { liver S1 }\end{array}$ & $\begin{array}{l}\text { Metastatic } \\
\text { tumor of } \\
\text { liver S5 }\end{array}$ & $\begin{array}{c}\text { Metastatic } \\
\text { tumor of } \\
\text { liver S6 }\end{array}$ & $\begin{array}{l}\text { Omentum } \\
\text { and } \\
\text { metastasis }\end{array}$ & $\begin{array}{c}\text { Hepatorenal } \\
\text { recess } \\
\text { tubercle }\end{array}$ \\
\hline$K I T$ & $\begin{array}{l}\text { c.2446_2448del } \\
\text { (p.D816del) }\end{array}$ & $19.2 \%$ & $9.7 \%$ & $21.8 \%$ & - & - & - & $24.2 \%$ & $25.8 \%$ \\
\hline NOTCH1 & $\begin{array}{l}\text { c.4423G>A } \\
\text { (p.D1475N) }\end{array}$ & $4.3 \%$ & - & - & - & - & - & - & - \\
\hline PIКЗСА & $\begin{array}{l}\text { c.323G>A } \\
(p . R 108 H)\end{array}$ & - & $5.0 \%$ & - & - & - & - & - & - \\
\hline
\end{tabular}

$\mathrm{CN}$, copy number. 


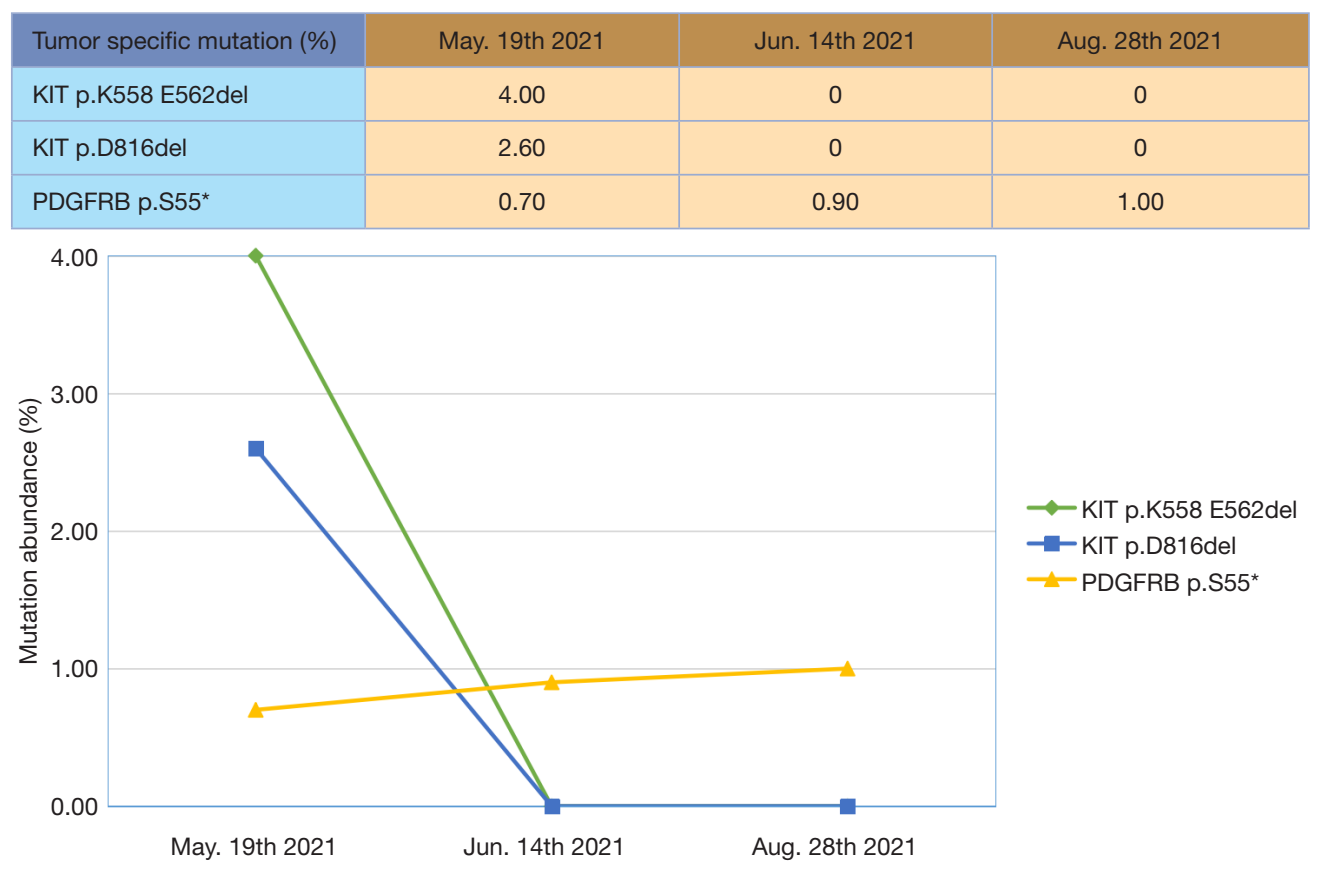

Figure 4 CtDNA level before taking RIP (May 19 ${ }^{\text {th }}, 2021$ ), at 2 weeks after RIP therapy (June $14^{\text {th }}, 2021$ ), and at 80 days after RIP therapy (August $\left.28^{\text {th }}, 2021\right)$. CtDNA, circulating tumor DNA; RIP, ripretinib.

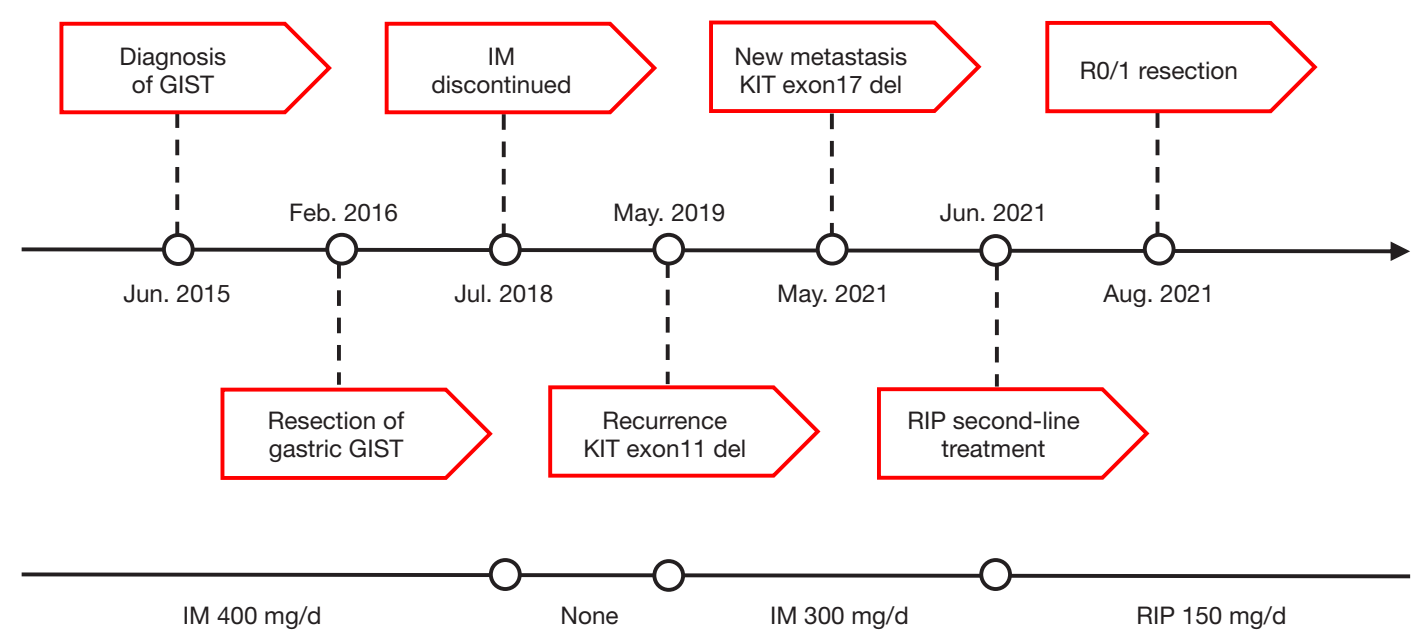

Figure 5 Flowchart of the oncological clinical history, prognosis, and treatments performed. GIST, gastrointestinal stromal tumor; IM, imatinib; RIP, ripretinib.

GIST receive clinical benefit from imatinib monotherapy, development of imatinib resistance is common, with more than half developing progressive disease in approximately 2 years (12), mostly attributed to the acquisition of secondary KIT mutations. These resistance mutations could be quite heterogeneous, with multiple secondary mutations from different patients, or even different lesions in a single lesion from one patient (13). Given this heterogeneity, an unmet need exists for a drug that inhibits a broad spectrum for KIT and PDGFRA mutants, thereby blocking the various resistance mutations and limiting the impact of further resistance mutations. In May 2020, oral RIP was first approved by the Food and Drug Administration (FDA) for patients with advanced GIST who had received prior 
treatment with $\geq$ three kinase inhibitors (14). RIP is the first switch-controlled TKI; it has been shown theoretically and confirmed by preclinical cellular proliferation testing that RIP can control broad-spectrum mutations in KIT and PDGFRA by inhibiting the switch pocket and activation ring switch.

For advanced GISTs that are resistant or intolerant to imatinib, sunitinib is the standard second-line treatment of progressive GISTs (15), which was likely to be ineffective due to secondary mutations in KIT exon 17 in this patient (16). After the failure of sunitinib treatment, the median progression-free survival (mPFS) of REG is 4.8 months, and the ORR is $4.5 \%$ (17). Studies have shown that some patients with KIT exon 17 mutation are resistant to REG (18), and the drug-related adverse reactions (including hand and foot skin reactions, hypertension, diarrhea, etc.) are relatively higher in Asian patients $(19,20)$. Based on the phase I study of RIP, the ORR and mPFS of second-line RIP treatment in patients with advanced GIST after imatinib resistance are $19.4 \%$ and 10.7 months, respectively (21). This suggests a potential applied value in terms of drug efficacy and safety. At the same time, RIP (type III evidence) was added to the Class III recommendation for second-line treatment in the 2021 edition of Chinese Society of Clinical Oncology guidelines for the diagnosis and treatment of GISTs. As can be seen from the entire treatment process in this case, our patient was successfully treated with RIP. The administration of RIP for systematic control and tumor shrinking gave the patient an opportunity to receive non-evidence disease (NED) cytoreductive surgery (22). At present, a Phase III trial (INTRIGUE, NCT03673501) of RIP versus sunitinib in advanced GIST after imatinib is undergoing, and we look forward to the final trial results.

Before the second operation, our patient had a good response to RIP, and the ctDNA turned negative. Imaging showed that the tumor focus was smaller than before, and most of the adverse reactions related to RIP treatment were grade 1 and tolerable, suggesting that the treatment was effective and safe. As a minimally invasive detection technique, peripheral blood ctDNA detection has the advantages of being non-invasive, safe, flexible, and convenient. It also overcomes tumor heterogeneity and allows a series of evaluations over time (23). It is widely used in the diagnosis of lung and breast cancers, the exploration of drug resistance mechanism, postoperative minimal residual diseases (MRD) monitoring, prognosis, and so on $(24,25)$.

For our patient, ctDNA was negative in the early stage of RIP treatment, which showed an effective treatment response earlier than imaging re-examination, and for a drug whose mechanism of drug resistance is not clear and relatively expensive, early efficacy evaluation is crucial to clinical decision-making. The therapeutic effect with dynamic monitoring of ctDNA in this patient was highly consistent with the imaging results, and showed an effective therapeutic response earlier than that of imaging (26). Although there are fewer ctDNA exfoliated in GISTs than other tumors, continuous monitoring can reflect the dynamic changes of the tumor when ctDNA is positive. It is a feasible and promising method to guide the treatment and predict the prognosis of patients with advanced GIST. It is expected to become a biomarker for non-invasive dynamic detection of GIST (10).

The target treatment effect of RIP was met before the operation. The genotyping of the resected specimen demonstrated that the newly appeared lesions (diaphragm, peritoneum, hepatorenal recess nodule) after the progression of first-line treatment were all with mutation in KIT exon 17 , which indicated that secondary drug-resistant tissues might be widely distributed (27). If imatinib was resumed postoperatively, it was likely to lead to tumor recurrence or metastasis in a short period of time, and thus, it was recommended to continue RIP treatment after comprehensive consideration. It should be pointed out that there was also a certain risk in the decision to continue postoperative RIP maintenance treatment. The mechanism of RIP resistance is not yet clear; if the patient has drug resistance in the future, the choice of subsequent treatment is still uncertain.

\section{Conclusions}

In summary, most GISTs will develop drug resistance after first-line imatinib treatment. When resistance is based on secondary gene mutations, carrying out individualized treatment according to the type of mutation and selecting targeted drugs with valid efficacy and safety should be considered. As a broad-spectrum KIT/PDGFRA inhibitor with an innovative mechanism and better safety, RIP is an important targeted therapeutic option in the treatment of advanced GIST. Dynamic monitoring of ctDNA level is feasible for treatment guidance and prognosis prediction of patients with advanced GIST.

\section{Acknowledgments}

Funding: None. 


\section{Footnote}

Reporting Checklist: The authors have completed the CARE reporting checklist. Available at https://atm.amegroups. com/article/view/10.21037/atm-21-6960/rc

Conflicts of Interest: All authors have completed the ICMJE uniform disclosure form (available at https://atm. amegroups.com/article/view/10.21037/atm-21-6960/coif). The authors have no conflicts of interest to declare.

Ethical Statement: The authors are accountable for all aspects of the work in ensuring that questions related to the accuracy or integrity of any part of the work are appropriately investigated and resolved. All procedures performed in this study were in accordance with the ethical standards of the institutional and/or national research committee(s) and with the Helsinki Declaration (as revised in 2013). Written informed consent was obtained from the patient for publication of this case report and any accompanying images. A copy of the written consent is available for review by the editorial office of this journal.

Open Access Statement: This is an Open Access article distributed in accordance with the Creative Commons Attribution-NonCommercial-NoDerivs 4.0 International License (CC BY-NC-ND 4.0), which permits the noncommercial replication and distribution of the article with the strict proviso that no changes or edits are made and the original work is properly cited (including links to both the formal publication through the relevant DOI and the license). See: https://creativecommons.org/licenses/by-nc-nd/4.0/.

\section{References}

1. Hirota S, Isozaki K, Moriyama Y, et al. Gain-of-function mutations of c-kit in human gastrointestinal stromal tumors. Science 1998;279:577-80.

2. D'Ambrosio L, Palesandro E, Boccone P, et al. Impact of a risk-based follow-up in patients affected by gastrointestinal stromal tumour. Eur J Cancer 2017;78:122-32.

3. Nemunaitis J, Bauer S, Blay JY, et al. Intrigue: Phase III study of ripretinib versus sunitinib in advanced gastrointestinal stromal tumor after imatinib. Future Oncol 2020;16:4251-64.

4. Mohammadi M, Gelderblom H. Systemic therapy of advanced/metastatic gastrointestinal stromal tumors: an update on progress beyond imatinib, sunitinib, and regorafenib. Expert Opin Investig Drugs 2021;30:143-52.

5. Smith BD, Kaufman MD, Lu WP, et al. Ripretinib (DCC2618) Is a Switch Control Kinase Inhibitor of a Broad Spectrum of Oncogenic and Drug-Resistant KIT and PDGFRA Variants. Cancer Cell 2019;35:738-751.e9.

6. Janku F, Abdul Razak AR, Chi P, et al. Switch Control Inhibition of KIT and PDGFRA in Patients With Advanced Gastrointestinal Stromal Tumor: A Phase I Study of Ripretinib. J Clin Oncol 2020;38:3294-303.

7. Blay JY, Serrano C, Heinrich MC, et al. Ripretinib in patients with advanced gastrointestinal stromal tumours (INVICTUS): a double-blind, randomised, placebocontrolled, phase 3 trial. Lancet Oncol 2020;21:923-34.

8. Serrano C, Vivancos A, López-Pousa A, et al. Clinical value of next generation sequencing of plasma cell-free DNA in gastrointestinal stromal tumors. BMC Cancer 2020;20:99.

9. Johansson G, Berndsen M, Lindskog S, et al. Monitoring Circulating Tumor DNA During Surgical Treatment in Patients with Gastrointestinal Stromal Tumors. Mol Cancer Ther 2021;20:2568-76.

10. Liu MC, Oxnard GR, Klein EA, et al. Sensitive and specific multi-cancer detection and localization using methylation signatures in cell-free DNA. Ann Oncol 2020;31:745-59.

11. von Mehren M, Joensuu H. Gastrointestinal Stromal Tumors. J Clin Oncol 2018;36:136-43.

12. Demetri GD, von Mehren M, Blanke CD, et al. Efficacy and safety of imatinib mesylate in advanced gastrointestinal stromal tumors. N Engl J Med 2002;347:472-80.

13. Parab TM, DeRogatis MJ, Boaz AM, et al. Gastrointestinal stromal tumors: a comprehensive review. J Gastrointest Oncol 2019;10:144-54.

14. Dhillon S. Ripretinib: First Approval. Drugs 2020;80:1133-8.

15. Demetri GD, Garrett CR, Schöffski P, et al. Complete longitudinal analyses of the randomized, placebocontrolled, phase III trial of sunitinib in patients with gastrointestinal stromal tumor following imatinib failure. Clin Cancer Res 2012;18:3170-9.

16. Heinrich MC, Maki RG, Corless CL, et al. Primary and secondary kinase genotypes correlate with the biological and clinical activity of sunitinib in imatinibresistant gastrointestinal stromal tumor. J Clin Oncol 2008;26:5352-9.

17. Demetri GD, Reichardt P, Kang YK, et al. Efficacy and safety of regorafenib for advanced gastrointestinal stromal tumours after failure of imatinib and sunitinib (GRID): 
an international, multicentre, randomised, placebocontrolled, phase 3 trial. Lancet 2013;381:295-302.

18. Lostes-Bardaji MJ, García-Illescas D, Valverde C, et al. Ripretinib in gastrointestinal stromal tumor: the long-awaited step forward. Ther Adv Med Oncol 2021;13:1758835920986498.

19. Xie G, Gong Y, Wu S, et al. Meta-Analysis of RegorafenibAssociated Adverse Events and Their Management in Colorectal and Gastrointestinal Stromal Cancers. Adv Ther 2019;36:1986-98.

20. Kim JJ, Ryu MH, Yoo C, et al. Phase II Trial of Continuous Regorafenib Dosing in Patients with Gastrointestinal Stromal Tumors After Failure of Imatinib and Sunitinib. Oncologist 2019;24:e1212-8.

21. Zalcberg JR. Ripretinib for the treatment of advanced gastrointestinal stromal tumor. Therap Adv Gastroenterol 2021;14:17562848211008177.

22. Martin-Broto J, Moura DS. New drugs in gastrointestinal stromal tumors. Curr Opin Oncol 2020;32:314-20.

23. Xu H, Chen L, Shao Y, et al. Clinical Application

Cite this article as: Huang S, Guo X, Xia Y, Ding L, Zhai E, Chen S, He Y, Cai S, Zhang X. Genotyping guided ripretinib directly after the progression of first-line imatinib therapy in advanced gastrointestinal stromal tumor: a case report. Ann Transl Med 2022;10(2):118. doi: 10.21037/atm-21-6960 of Circulating Tumor DNA in the Genetic Analysis of Patients with Advanced GIST. Mol Cancer Ther 2018;17:290-6.

24. Chae YK, Oh MS. Detection of Minimal Residual Disease Using ctDNA in Lung Cancer: Current Evidence and Future Directions. J Thorac Oncol 2019;14:16-24.

25. Magbanua MJM, Swigart LB, Wu HT, et al. Circulating tumor DNA in neoadjuvant-treated breast cancer reflects response and survival. Ann Oncol 2021;32:229-39.

26. Yang J, Wang X, Lu J, et al. Genomic Profiling of Circulating Tumor DNA from Patients with ExtensiveStage Small Cell Lung Cancer Identifies Potentially Actionable Alterations. J Cancer 2021;12:5099-105.

27. Vincenzi B, Nannini M, Badalamenti G, et al. Imatinib rechallenge in patients with advanced gastrointestinal stromal tumors following progression with imatinib, sunitinib and regorafenib. Ther Adv Med Oncol 2018;10:1758835918794623.

(English Language Editor: A. Kassem) 